\title{
A Rare Cause of Hoarseness of Voice: Lipoid Proteinosis of the Larynx
}

\author{
${ }^{1}$ Santosh Kumar Swain, ${ }^{2}$ Maitreyee Panda, ${ }^{3}$ Nibedita Patro, ${ }^{4}$ Mahesh Chandra Sahu
}

\begin{abstract}
Lipoid proteinosis (LP) is a rare genetic disease with autosomal recessive inheritance. It most often involves deposition of periodic acid Schiff positive hyaline material in skin, oral mucosa, larynx and other tissues. But it also involves the central nervous system, lungs, lymph nodes and striated muscles. Hoarseness, small papules on the eyelid border (moniliform blepharosis), enlarged tongue, waxy skin, and diffuse verrucous skin colored or yellowish papules and plaques on traumatized areas and oral mucosa are the most common features leading to the clinical diagnosis of LP. We present the case report of a 12-year-old boy with significant hoarseness, inability to protrude the tongue, beaded papules along the eyelid margins, and scarring of the skin. Of his two sisters, one had the same symptoms but with less clinical severity and the other had no features of LP.
\end{abstract}

Keyword: Consanguinity, Laryngeal manifestation, Hoarseness, Lipoid proteinosis, Urbach-Wiethe disease.

How to cite this article: Swain SK, Panda M, Patro N, Sahu MC. A Rare Cause of Hoarseness of Voice: Lipoid Proteinosis of the Larynx. Int J Phonosurg Laryngol 2014;4(1):23-26.

\section{Source of support: Nil}

\section{Conflict of interest: None}

\section{INTRODUCTION}

Lipoid proteinosis (LP) or Urbach Wiethe disease (UWD) ${ }^{1}$ is characterized by laryngeal manifestation of hoarseness, whitish papules on the eyelids, acneform scars which are particularly evident on the face and the limbs and often of a relatively discrete nature in the skin and in the mucous membranes of the mouth, pharynx and larynx. ${ }^{2}$ The first case of LP was reported by Seibenmann in 1908. Initially, this disorder was observed in South Africa, where the gene responsible was introduced in the mid-17th century by a

\footnotetext{
${ }^{1}$ Associate Professor, ${ }^{2,3}$ Assistant Professor, ${ }^{4}$ Research Associate

${ }^{1}$ Department of ENT, Institute of Medical Sciences and SUM Hospital, Bhubaneswar, Odisha, India

${ }^{2,3}$ Department of Dermatology, Institute of Medical Sciences and SUM Hospital, Bhubaneswar, Odisha, India

${ }^{4}$ Department of Central Research Lab, Institute of Medical Sciences and SUM Hospital, Bhubaneswar, Odisha, India

Corresponding Author: Santosh Kumar Swain, Associate Professor, Department of ENT, Institute of Medical Sciences and SUM Hospital, Bhubaneswar, Odisha, India, Phone: 06742386292 e-mail: santoshvoltaire@yahoo.co.in
}

German settler and his sister. ${ }^{3-5}$ This name was subsequently modified to 'lipoid proteinosis' to avoid confusion with other lipoidoses. ${ }^{6}$

Lipoid proteinosis is a rare autosomal recessive disorder of variable severity that may involve the upper respiratory tract and internal organs. It may display different clinical manifestations based on the site of involvement. ${ }^{7}$ Lipoid proteinosis is caused by homozygous or compound heterozygous mutations in the extra cellular matrix-1 (ECM-1) gene located on chromosome 1q21. ${ }^{1,8}$ The ECM-1 gene encodes an important structural component of the basement membrane and extracellular matrix. ${ }^{8-10}$ The dermatological manifestations of LP, such as warty skin, scarring, and mucosal thickening arise from the loss of protein-protein interactions due to ECM-1 gene mutations. ${ }^{8,11}$ The hyaline like material is periodic acid Schiff(PAS) positive and diastase resistant and is believed to be the result of the deposition of noncollagenous proteins and glycoproteins. ${ }^{12}$ In approximately two thirds of cases, voice change secondary to laryngeal involvement occurring at birth or early in infancy is the first manifestation of the disease. The most characteristic symptom, hoarseness, is found since birth. There is often thickening of lower lip and the tongue which causes its reduced motility. Small nodules, often not more than one millimeter in diameter, are found along the edge of the eyelids are found, and similar changes are observed in the nasopharynx, tongue, and vocal cords resulting in characteristic severe fibrosis and hoarseness. A few cases of LP associated with mild mental retardation have been reported. Other rarely associated neurologic abnormalities include complex partial seizures, amnesia, and mood disturbances, which often begin in the second decade of life. ${ }^{8}$ Although more than 250 cases have been reported, the occurrence of the disease in siblings is very rare. Interestingly, most familial cases have been reported from South Asia, including India, Saudi Arabia, Iran, Kuwait and Turkey where consanguineous marriages are commonly seen. ${ }^{13}$ Here, we present a case report of LP in a 12-year-old boy born of consanguineous marriage.

\section{CASE REPORT}

A 12-year-old tribal boy reported to the outpatient department of ENT of our institute with chief complaints of hoarseness of voice since infancy. He also had restricted tongue protrusion and speech impairment. The patient also complained of scarring of the skin over the face (Fig. 1) and 
extremities since infancy. The laryngeal examination showed bilaterally thickened vocal cords and swollen arytenoids (Fig. 2). Both vocal cords were mobile and other parts of larynx were normal. The skin lesions were evaluated by the dermatologist. They appeared as recurrent episodes of pustules and on healing, these pustules left pitted scars. On examinations, the margins of eyelids had become thickened, beaded and irregular (Fig. 3). There was no history of headache, epilepsy or visual disturbances and his intelligence was normal. There was no such disease among the parents but his younger sibling had similar complaints. The parents gave history of consanguineous marriage. Among his two sisters, one had the same symptoms but with less clinical severity while the other had no features of LP.

Routine laboratory tests included complete blood count, liver and kidney function tests, serum lipid profile, serum porphyrin level and urine, which were all within normal

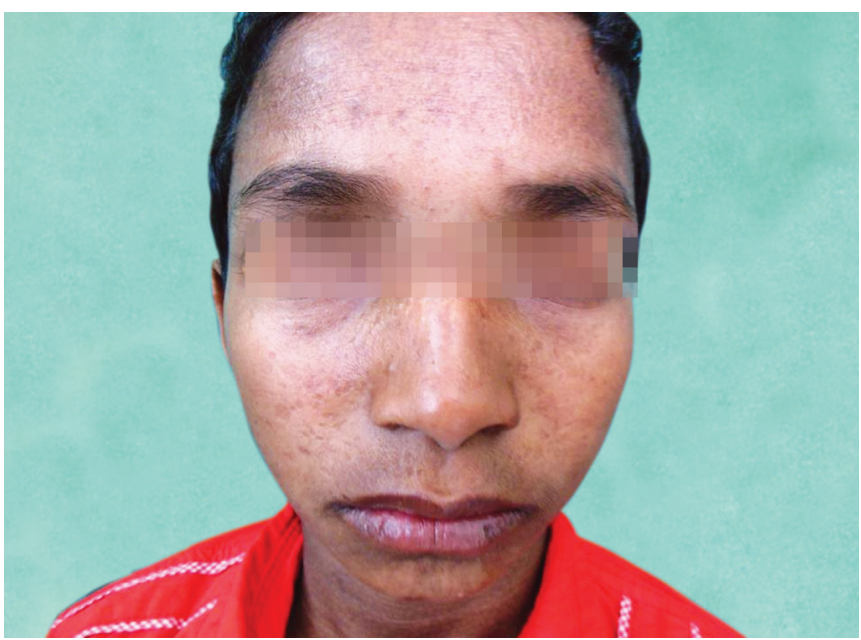

Fig. 1: The patient with scarring of the skin over the face

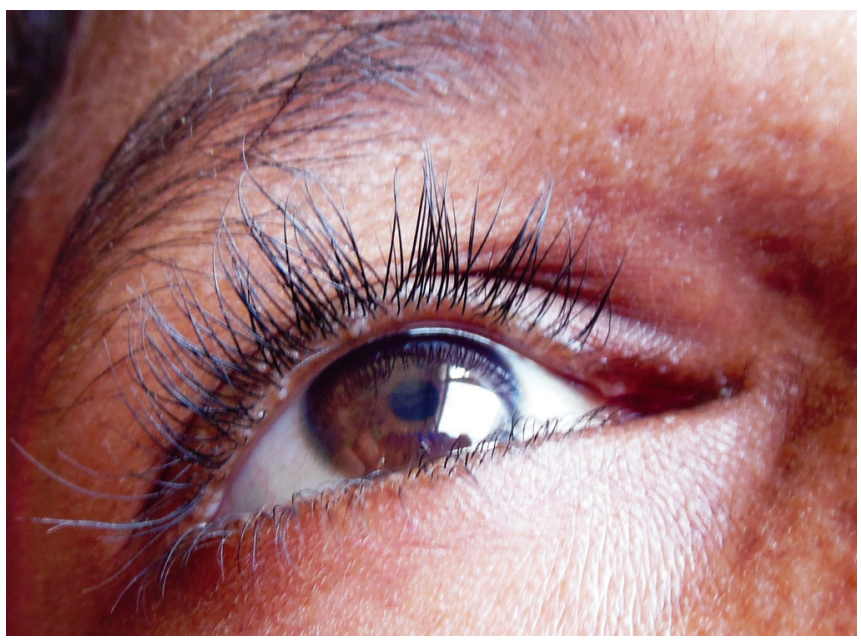

Fig. 3: Margins of the eyelids showing small, irregular, beaded and flesh-colored papules limits. The patient had undergone release of tongue tie for improvement of speech. Laryngeal biopsy was taken from thickened vocal cord under general anesthesia. The histopathological study (Fig. 4) confirmed the diagnosis of LP.

\section{DISCUSSION}

In 1908, the first case of Urbach-Wiethe disease was reported by Seibenmann, a professor of otolaryngology in Basel, Switzerland. In 1925, Friedrich Miescher, a Swiss dermatologist, reported on three similar patients. ${ }^{14,15}$ An official report of the disease was first described in 1929 by a Viennese dermatologist and otorhinolaryngologist, Urbach and Wiethe. ${ }^{16}$ Its original name of 'lipoidosis cutis et mucosae' was changed to 'lipoid proteinosis cutis et mucosae' due to Urbach's belief that the condition was due to abnormal lipid and protein deposits within the tissues. ${ }^{16}$ Some have

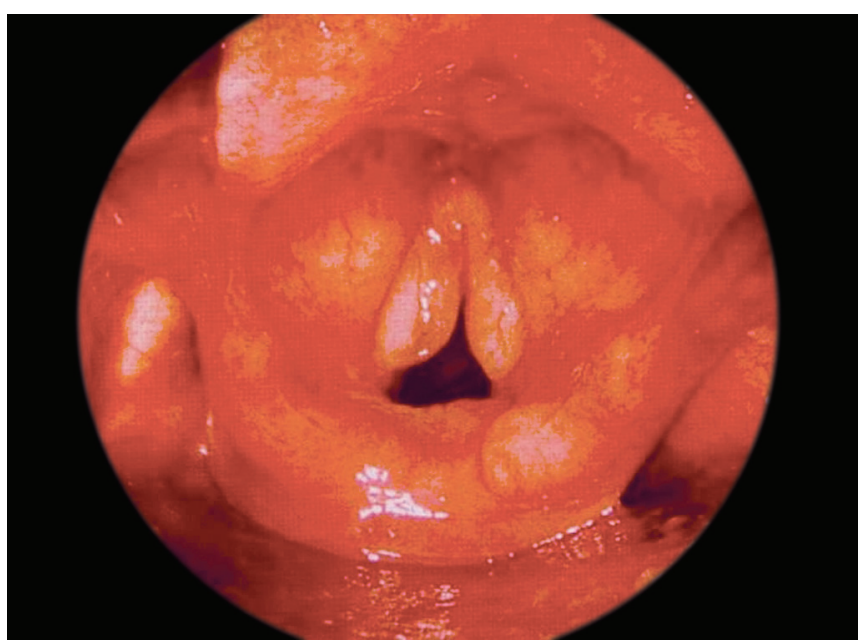

Fig. 2: The laryngeal examination showed thickened bilateral vocal cords and swollen bilateral arytenoids

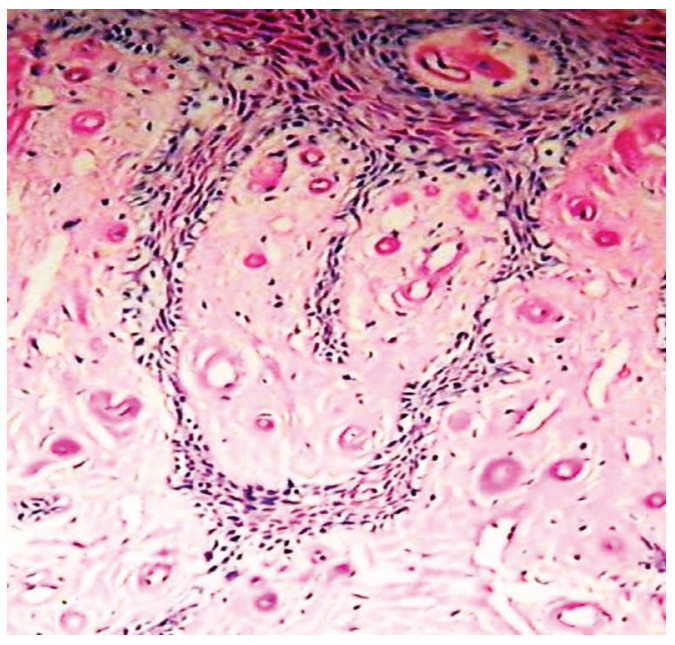

Fig. 4: The histopathological picture of tissue from vocal cord 
debated as to whether or not the disease is actually a form of mucopolysaccharidosis, amyloidosis, or even porphyria. The discovery of the Urbach-Wiethe disease causing mutation to the ECM-1 gene has now provided a definitive way to differentiate Urbach-Wiethe disease from other conditions. The diagnosis can be established on the basis of characteristic clinical features and confirmed by histopathology. ${ }^{16}$

Lipoid proteinosis disease is very rare, In medical literature, there are only about 300 reported cases. ${ }^{17}$ Almost a quarter of these are from South Africa. Though Urbach-Wiethe disease is found worldwide, many of these are in patients of Dutch, German and Khoisan ancestry. ${ }^{16,17}$ This high frequency is thought to be due to the founder effect. ${ }^{18}$ Due to its recessive genetic cause and the ability to be a carrier of the disease without symptoms, Urbach-Wiethe disease often runs in families. In some regions of South Africa, up to one in 12 individuals may be carriers of the disease. ${ }^{16}$ Most of the case studies involving Urbach-Wiethe disease patients involve only one to three cases and these cases are often in the same family. Due to its low incidence, it is difficult to find a large enough number of cases to adequately study the disease.

Urbach-Wiethe disease is typically not a life-threatening condition. ${ }^{17}$ The life expectancy of these patients is normal as long as the potential side effects of thickening mucosa, such as respiratory obstruction are properly addressed. ${ }^{19}$ Although this may require a tracheostomy or laser surgery for getting airway, such steps can help to ensure that individuals with Urbach-Wiethe disease are able to live a full life. Oral dimethyl sulfoxide has been shown to reduce skin lesions, helping to minimize discomfort for these individuals. ${ }^{16}$

The exact etiology and pathogenesis of LP are not known. Mutations in the gene encoding ECM-1 gene on band 1q21 have been identified as the cause of LP. ${ }^{20}$ The different manifestations of LP are associated with extensive deposition of noncollagenous proteins and glycoproteins in the larynx, skin and other organs. ${ }^{16}$

Diffuse infiltration of the pharynx and larynx with hyaline material may cause respiratory distress. ${ }^{21}$ A case report presented with speech difficulty and xerostomia but had no upper respiratory distress or dyspnea. Infiltration of the tongue and frenulum results in woody firmness and impaired mobility. Hyaline material can also deposit in the conjunctiva, cornea, trabeculum and retina. ${ }^{22}$ Corneal opacity or secondary glaucoma due to infiltration in the trabeculum may present later. ${ }^{23}$ Calcification of intracerebral parasellar or hippocampal gyri may sometimes be associated with epilepsy, behavioral changes, learning difficulties. ${ }^{24}$ Histochemical diagnosis is now possible by using an antibody to ECM-1. ${ }^{25}$ The differential diagnosis of this pathological condition should consider erythropoietic protoporphyria, the lesions of which are restricted to solar exposed areas and there is involvement of the mucous membrane. ${ }^{26}$

The first clinical sign is often hoarseness of voice, which presents at birth, or early childhood and becomes prominent within the first few years of life and can progress to complete aphonia. Mucosa of the lips, tongue and pharynx soon develop firm and yellow-white infiltrates. ${ }^{26-28}$ The tongue is enlarged and becomes firm on palpation. Skin changes become prominent in early life with the development of yellow-brown nodules on the face and lips. Scattered lesions resembling atrophic, pitted, acne scars may be seen on the face as well as on non-acne prone regions of the body. Deposition of yellow materials induce a marked thickening of the facial skin with deep wrinkles, which may resemble solar elastosis. Translucent keratotic papules are seen on the elbows and knees. ${ }^{29}$ The skin shows increased susceptibility to injury from minor trauma and infection with recurrent attacks of impetigo, often bullous in nature. ${ }^{11}$

The eyelid lesions, which are pathognomonic for the disease, are described in $50 \%$ of cases. ${ }^{11}$ These lesions appear as small, flesh-colored papules seen along the margins of the upper and lower eyelid. The appearance of these papules is variously described as 'string of beads' or 'eyelid beading' and is also known as 'moniliform blepharosis'. 11,30 Characteristic bilateral calcifications or ossifications are found in temporal lobes in 50 to $75 \%$ of cases. Dental abnormalities are seen in $30 \%$ cases $^{4}$ and epilepsy may also be observed. The exact pathogenesis of this disease is not clear but has been postulated to be as a result of either a lysosomal storage disorder involving multiple enzyme defects or from a disturbance in collagen synthesis. ${ }^{16}$ Recent studies have shown that it is the result of altered expression of ECM-1 gene. $^{18}$

Histologically, LP is characterized by deposition of a PAS-positive, diastase resistant material at the level of the basement membrane, papillary dermis, surrounding blood vessels, and around adnexal epithelia, especially sweat coils. Ultrastructural examination reveals concentric rings of excess basement membrane surrounding blood vessels and irregular reduplication of lamina densa at dermoepidermal junction resulting in an onion-skin appearance. Presently, there is no effective treatment available for LP. Microlaryngoscopy and excision of deposits on vocal cords may be done to improve the voice. Respiratory obstruction is rare and may need tracheostomy. Therapeutic approaches reported in the literature include oral steroids, dimethyl sulfoxide, intralesional heparin, etretinate and pencillamine. $^{31}$ 


\section{CONCLUSION}

Hoarseness of voice since infancy, multiple beaded papules along eyelid margins, restricted mobility of tongue, thickened protuberant lips, thickened oral mucosa, and scarring of the skin over face clinched the diagnosis of LP. Scars over the face may need differentiating from erythropoietic porphyria. Absence of photosensitivity and presence of PAS positive material on sun protected area and around vessels and superficial dermis delineate this condition. It is very important to consider this disease in the differential diagnosis of hoarseness because it might lead to life-threatening airway compromise. We herewith report this case for its rarity with very typical diagnostic features and the need for multispecialty approach in managing the patient.

\section{REFERENCES}

1. Urbach E, Wiethe C. Lipoidosis cutis et mucosae. Virchows Arch A Pathol Anat 1929;273:285-319.

2. Xu W, Wang L, Zhang L, Liu HG, Zan F, Hu R, Liu WB, Han DM. Manifestation and treatment of lipoid proteinosis in larynx. Zhonghua Er Bi Yan Hou Tou Jing Wai Ke Za Zhi 2010; 45(4):301-304.

3. Kaur V, Singh G. Lipoid proteinosis. Indian J Dermatol Venereol Leprol 1992;58(6):399-400.

4. Emsley RA, Paster L. Lipoid proteinosis presenting with neuropsychiatric manifestations. J Neurol Neurosurg Psychiatry 1985;48(12):1290-1292.

5. Heyl T. Genealogical study of lipoid proteinosis in South Africa. Br J Dermatol 1970; 83(3):338-340.

6. Banerjee S, Jana S, Azad AK, Sinha R, Datta J, Banerjee R, Dutta S, Chanda M, Gangopadhyay DN. Lipoid proteinosis with vesicular eruptions and hypertrichosis: rare associations. Indian J Dermatol 2005;50(2):98-100.

7. Kucuk U, Cukurova I, Bayol U, Erdogan IG, Hacioglu N, Bicakci C. Urbach-Wiethe disease (lipoid proteinosis). Indian J Pathol Microbiol 2012;55(3):375-376.

8. Salih MA, Abu-Amero KK, Alrasheed S, Alorainy IA, Liu L, McGrath JA, Van Maldergem L, Al-Faky YH, AlSuhaibani AH, Oystreck DT, et al. Molecular and neurological characterizations of three Saudi families with lipoid proteinosis. BMC Med. Genet 2011;12:31

9. Hamada T, Wessagowit V, South AP, Ashton GH, Chan I, Oyama N, Siriwattana A, Jewhasuchin P, Charuwichitratana S, Thappa $\mathrm{DM}$, et al. Extracellular matrix protein 1 gene (ECM1) mutations in lipoid proteinosis and genotype-phenotype correlation. J Invest Dermatol 2003;120(3):345-350.

10. Sercu S, Zhang M, Oyama N, Hansen U, Ghalbzouri AE, Jun G, Geentjens K, Zhang L, Merregaert JH. Interaction of extracellular matrix protein 1 with extracellular matrix components: ECM1 is a basement membrane protein of the skin. J Invest Dermatol 2008;128(6):1397-1408.

11. Staut C, Naidich T. Urbach-Wiethe disease (lipoid proteinosis). Pediatr Neurosurg 1998;28(4):212-214.

12. Touart DM, Sau P. Cutaneous deposition diseases. Part I. J Am Acad Dermatol 1998;39(2):149-171.

13. Parimalam K, et al. Lipoid proteinosis in a child with recurrent respiratory infection. J Indian Soc Teledermatol 2009;3(4):4-6.
14. Muda AO, Paradisi M, Angelo C, Mostaccioli S, Atzori F, Puddu P, Faraggiana T. Lipoid proteinosis: clinical histologic and ultrastructural investigations. Cutis 1995;56(4): 220-224.

15. Farolan MJ, Ronan SG, Solomon LM, Loeff DS. Lipoid proteinosis: case report. Pediatr Dermatol 1992;9(3):264-267.

16. Hamada T, McLean WHI, Ramsay M, Ashton GHS, Nanda A, et al. Lipoid proteinosis maps to $1 \mathrm{q} 21$ and is caused by mutations in the extracellular matrix protein 1 gene (ECM1). Hum Mol Genet 2002;11(7):833-840.

17. Di Giandomenico S, Masi R, Cassandrini D, EI-Hachem M, De Vito R, Bruno C, Santorelli FM. Lipoid proteinosis: case report and report and review of the literature. Acta Otorhinolaryngol Ital 2006;26(3):162-167.

18. Chan I, Liu L, Hamada T, Sethuraman G, McGrath JA. The molecular basis of lipoid proteinosis: mutations in extracellular matrix protein 1. Experimental Dermatology 2007;16(11): 881-890

19. Appenzeller S, Chaloult E, Velho P, MacEdo DS E, Zanardi AVN, Cendes F, Li LM. Amygdalae calcifications associated with disease duration in lipoid proteinosis. J Neuroimaging 2006;16(2):154-156.

20. Van Hougenhouck-Tulleken W, Chan I, Hamada T, Thornton H, Jenkins T, McLean WH, McGrath JA, Ramsay M. Clinical and molecular characterizations of lipoid proteinosis in Namqualand, South Africa. Br J Dermatol 2004;151(2): 413-423.

21. Ramsay ML, Tschen JA, Wolf JE. Lipoid proteinosis. Int J Dermatol 1985;24(1):230-232.

22. Keen A, Hassan I, Manaan Q, Masood Q. Lipoid proteinosis: Case report and a brief review. J Pak Assoc Dermatol 2012; 22:157-162.

23. Dinakaran S, Desai SP, Palmer IR, Parsons MA. Lipoid proteinosis: clinical features and electron microscopic study. Eye 2001; 15:666-668

24. Rahalkar M, Kelkar A, Gharpuray M. Lipoid proteinosis. Acta Dermatoven APA 2004;13:131-134.

25. Chan I, South AP, Mc Grath JA, Oyama N, Bhogal BS, Black MM, Hamada T. Rapid diagnosis of lipoid proteinosis using an anti-extracellular matrix protein (ECM1) antibody. J Dermatol Sci 2004;35(2):151-153.

26. Bozdag KE, Gul Y, Karaman A. Lipoid Proteinosis. Int J Dermatol 2000;39(3):203-204.

27. Sarkany RPE, Breathnach SM, Seymour CA, Burns T, Breathnach S, Cox N, Griffths CH. Metabolic and nutritional disorders. In editors. Rook's Textbook of Dermatology. 7th ed. Oxford: Blackwell Science; 2004;3:56-57.

28. Dyer JA. Wolff K, Goldsmith LA, Katz SI, Gilchrest BA, Paller AS, Leffell DJ, Lipoid proteinosis. In: editors. Fitzpatrick's dermatology in general medicine. 7th ed. New York: McGrawHill; 2008;2:1288-1292.

29. Fransway AF, Muller SA. Moschell SL, Hurley HJ. Neurocutaneous diseases. In: Moschella SL, Hurley HJ, editors. Dermatology. 3rd ed. Philadelphia: WB Saunders; 1992. 2054 p.

30. Thappa DM, Gupta S. Eyelid beaing - a useful diagnostic clue for lipoid proteinosis. Indian Pediatr 2001;38:97-99.

31. Kaya TI, Kokturk A,Tursen U, Ikizoglu G, Polat 1. D-penicillamine treatment for lipoid proteinosis. Pediatr Dermatol 2002; 19(4):359-362. 